\title{
Development of tissue-engineered models of oral dysplasia and early invasive oral squamous cell carcinoma
}

\author{
HE Colley*,', V Hearnden ${ }^{1,2}$, AV Jones ${ }^{3}$, PH Weinreb ${ }^{4}$, SM Violette ${ }^{5}$, S MacNeil ${ }^{2}$, MH Thornhill' and \\ C Murdoch'
}

'Academic Unit of Oral and Maxillofacial Medicine and Surgery, School of Clinical Dentistry, University of Sheffield, Claremont Crescent, Sheffield SIO 2TA, UK; ${ }^{2}$ Department of Materials Science and Engineering, The Kroto Research Institute North Campus, University of Sheffield Broad Lane, Sheffield S3 7HQ, UK: ${ }^{3}$ Academic Unit of Oral and Maxillofacial Pathology, School of Clinical Dentistry, University of Sheffield, Claremont Crescent, Sheffield SIO 2TA, UK; ${ }^{4}$ Biogen Idec Inc., 14 Cambridge Center, Cambridge, MA 02142, USA; ${ }^{5}$ Stromedix Inc., I Canal Park, Suite II 20, Cambridge, MA 02 I II, USA

BACKGROUND: Current organotypic models of dysplasia and oral squamous cell carcinoma (OSCC) lack the complexity that mimics in vivo tissue. Here we describe a three-dimensional in vitro model of the oral epithelium that replicates tumour progression from dysplasia to an invasive phenotype.

METHODS: The OSCC cell lines were seeded as a cell suspension (D20, Cal27) or as multicellular tumour spheroids (FaDu) with oral fibroblasts on to a de-epidermised acellular dermis to generate tissue-engineered models and compared with patient biopsies. RESULTS: The D20 and Cal27 cells generated a model of epithelial dysplasia. Overtime Cal27 cells traversed the basement membrane and invaded the connective tissue to reproduce features of early invasive OSCC. When seeded onto a model of the normal oral mucosa, FaDu spheroids produced a histological picture mimicking carcinoma in situ with severe cellular atypia juxtaposed to normal epithelium.

CONCLUSION: It is possible to culture in vitro models with the morphological appearance and histological characteristics of dysplasia and tumour cell invasion seen in vivo using native dermis. Such models could facilitate study of the molecular processes involved in malignant transformation, invasion and tumour growth as well as in vitro testing of new treatments, diagnostic tests and drug delivery systems for OSCC.

British Journal of Cancer (20 I I) 105, 1582- I592. doi: 10.1038/bjc.20 I I.403 www.bjcancer.com

Published online II October 20II

(c) 20II Cancer Research UK

Keywords: squamous cell carcinoma; oral mucosa; dysplasia; invasion; tissue engineered

Head and neck squamous cell carcinoma (HNSCC), which includes oral squamous cell carcinoma (OSCC), is the sixth most common malignancy worldwide (Argiris et al, 2008), and despite improved patient outcomes in a range of cancers the prognostic implications of HNSCC remain poor. With no established screening methods, visual identification of oral cancers is imperative for early detection, although recent developments of aneuploidy analysis for premalignant lesions may help to predict those lesions at risk of developing malignancy (Torres-Rendon et al, 2009; Bradley et al, 2010). Premalignant lesions have a variety of clinical presentations and may present as leukoplakia (white patch) or erythroplakia (red patch). Although erythroplakia is more likely to show histological features of dysplasias that then progress to OSCC, only a small proportion of all premalignant lesions progress to malignancy (Reibel, 2003).

Numerous aetiological factors are involved in the transformation of normal oral mucosa (NOM) to premalignant dysplastic lesions that may then develop into oral carcinoma (Jefferies and Foulkes, 2001; Leemans et al, 2011). Using molecular techniques to

*Correspondence: Dr HE Colley; E-mail: h.colley@sheffield.ac.uk Received I July 2011; revised 30 August 201 I; accepted 13 September 201 I; published online II October 20 II examine loss of heterozygosity, gene mutations and gene transcription patterns, investigators have shown that oral carcinogenesis is a progressive multistep process resulting from the clonal expansion of a cancer stem cell with a TP53 mutation. Initially, a small patch of these mutated cells are present in the oral mucosa. These cells then acquire additional cancer-related genetic alterations and expand to form a larger field of abnormal cells that, with the acquisition of further genetic changes, then progress to invasive cancer (Califano et al, 1996, 2000; Braakhuis et al, 2003). In fact, current evidence suggests that oral premalignant lesions share genetic alterations and transcription profiles that are closer to the malignant lesions they go on to form than the transcription profiles of premalignant lesions that do not progress to cancer (Ha et al, 2003; Hunter et al, 2006). Thus, it seems that OSCC genetic signatures are already embedded in the premalignant cells that are destined to progress to malignancy.

Histological analysis of epithelial dysplasia is graded as mild, moderate or severe depending on the extent of atypia in the oral mucosa. Full-thickness dysplasia is classified as carcinoma in situ and only becomes an early invasive OSCC once tumour cells have penetrated through the basement membrane and infiltrated into the connective tissue. The clinical appearance of a dysplastic lesion is not a good guide to the level of dysplasia, and hence potential malignancy or malignancy can only be assessed by biopsy and 
histopathological evaluation. Despite recent therapeutic developments (Mao et al, 1998; Rudin et al, 2003; Rhee et al, 2004), there is currently no effective treatment for dysplasia but to reduce the associated risk factors for malignant change, such as smoking and alcohol consumption, and to monitor for malignant progression.

Although a valuable tool in oral cancer research, monolayer cultures of epithelial cells do not achieve the complexity of the oral mucosa in vivo. Important features innate to this organised tissue, such as cell-cell interactions, control of proliferation, differentiation, the deposition of a basement membrane and the controlling influence of the connective tissue (Moharamzadeh et al, 2007), are all lost in monolayer culture. Xenograft animal tumour models or tumours generated by epithelial transformation using chemical carcinogens have been successful in identifying important genes, molecules and mechanisms involved in oral cancer development and progression (Kim, 2009). Although several in vivo models for studying head and neck are available, none are fully satisfactory as they are often difficult to establish, produce varying results and raise important questions about the genetic differences between humans and animals, and whether xenograft or chemically induced tumour models are representative of human oral cancer (Prime et al, 1986; Kim, 2009).

Tissue-engineered three-dimensional (3D) models of the NOM are now well established for in vitro investigations (reviewed in Moharamzadeh et al, 2007) and have more recently been used for clinical applications (Bhargava et al, 2008). The keratinocyte organotypic co-culture model originally developed by Fusenig et al (1983) has been used by investigators to mimic oral dysplasia or cancer (Nystrom et al, 2005; Costea et al, 2006; Vigneswaran et al, 2006; Gaballah et al, 2008; Marsh et al, 2011). This method involves the culture of keratinocytes at an air-to-liquid interface on a fibroblast-containing collagen type I matrix. Interactions between the mesenchyme and epithelium are essential for normal epithelium development and maintenance. Crosstalk between the stroma and the overlying epithelium is known to influence a number of processes including keratinocyte proliferation, migration, differentiation and the formation of a basement membrane at the epithelial-dermal junction (EDJ) by synthesis of extracellular matrix (ECM) components (Saintigny et al, 1993). It is therefore not surprising that the stromal microenvironment is known to play a significant role in tumour invasion and progression (Mueller and Fusenig, 2004; Marsh et al, 2011). However, the basic homogeneous structure of the connective tissue (Wolf et al, 2009) and lack of a native basement membrane (Chung et al, 1997; Yadev et al, 2011) in collagen-based models allows only a simplistic representation of the native stromal component. Mucosal models that utilise a more complex, native, connective tissue containing a defined basement membrane to investigate oral dysplasia and invasive carcinoma may provide a greater insight into the molecular mechanisms controlling premalignant dysplasia and invasion in vivo.

The aim of this study was to develop and optimise a tissueengineered, full-thickness model of squamous cell carcinoma of the oral mucosa from a dysplastic phenotype to early invasion using native human dermis. Such models could facilitate study of the mechanistic aspects of disease processes that are involved in malignant transformation, early invasion and tumour growth as well as facilitate final stage in vitro testing of new treatments, diagnostic tests and drug delivery systems for OSCC.

\section{MATERIALS AND METHODS}

\section{Culture of HNSCC cell lines}

This study used the following HNSCC cell lines: Cal27 (American Tissue Culture Collection (Manassas, VA, USA), CRL-2095) that was originally isolated from a 56-year-old Caucasian male with a squamous cell carcinoma of the tongue (Gioanni et al, 1988); FaDu (LGC Promochem, Middlesex, UK) that was isolated from a hypopharyngeal tumour (Rangan, 1972); DOK (ECACC, Health Protection Agency Culture Collections, Salisbury, UK), a dysplastic oral keratinocyte cell line that was originally isolated from the dorsal tongue of a 57-year-old male (Chang et al, 1992); and D20 that was derived from a lateral tongue dysplasia (McGregor et al, 1997). Cal27 and DOK cells were routinely cultured in Dulbecco's modified Eagle's medium (DMEM) and FaDu cells in RPMI-1640 supplemented with $10 \%(\mathrm{v} / \mathrm{v})$ fetal calf serum (FCS; BioSera, East Sussex, UK), $2 \mathrm{~mm}$ L-Glutamine, $100 \mathrm{IU} \mathrm{ml}^{-1}$ penicillin and $100 \mu \mathrm{g} \mathrm{ml}^{-1}$ streptomycin (Sigma, Poole, UK). Medium for the culture of DOK cells was also supplemented with $5 \mu \mathrm{g} \mathrm{ml}^{-1}$ hydrocortisone. D20 cells were cultured in flavin- and adenineenriched medium: DMEM and Ham's F12 medium in a $3: 1(\mathrm{v} / \mathrm{v})$ ratio supplemented with $10 \%(\mathrm{v} / \mathrm{v})$ FCS, $0.1 \mu \mathrm{M}$ cholera toxin, $10 \mathrm{ng} \mathrm{ml}^{-1}$ of epidermal growth factor (EGF), $0.4 \mu \mathrm{g} \mathrm{ml}^{-1}$ hydrocortisone, $0.18 \mathrm{~mm}$ adenine, $5 \mu \mathrm{g} \mathrm{ml}^{-1}$ insulin, $5 \mu \mathrm{g} \mathrm{ml}^{-1}$ transferrin, $2 \mathrm{~mm}$ glutamine, $0.2 \mu \mathrm{m}$ triiodothyronine, $0.625 \mu \mathrm{g} \mathrm{ml}^{-1}$ amphotericin $\mathrm{B}, 100 \mathrm{IU} \mathrm{ml}^{-1}$ penicillin and $100 \mu \mathrm{g} \mathrm{ml}^{-1}$ streptomycin (Allen-Hoffmann and Rheinwald, 1984).

\section{Flow cytometry}

Keratinocytes were removed from tissue culture flasks nonenzymatically, centrifuged at $250 \mathrm{~g}$ for $5 \mathrm{~min}$ and re-suspended at $1 \times 10^{7}$ cells per $\mathrm{ml}$ in cold PBS supplemented with $0.1 \%$ BSA, $0.1 \%$ sodium azide (FACs buffer) and kept on ice. Cells $\left(5 \times 10^{5}\right.$ cells) were incubated for $30 \mathrm{~min}$ on ice with $10 \mu \mathrm{g} \mathrm{ml}^{-1}$ anti- $\alpha \mathrm{v} \beta 6$ mouse monoclonal antibody (clone 6.3G9) or IgG isotype-matched control. Following washes with FACs buffer, cells were incubated with AlexaFlour 488-conjugated anti-mouse antibody (Invitrogen, Paisley, UK) for $30 \mathrm{~min}$ on ice in the dark, then washed twice and re-suspended with FACs buffer. Flow cytometry was performed using a FACsCalibur (Becton Dickinson, San Jose, CA, USA); propidium iodide was used to gate out nonviable cells and data were analysed using CellQuest Software (Becton Dickinson).

\section{Multicellular tumour spheroid (MCTS) production}

Multicellular tumour spheroid were generated from $\mathrm{FaDu}$ cells using the liquid overlay method as previously described (Carlsson and Yuhas, 1984). Briefly, $100 \mu \mathrm{l}$ of $\mathrm{FaDu}$ cells $\left(1.2 \times 10^{5}\right.$ per $\left.\mathrm{ml}\right)$ were added to each well of a 96-well plate previously coated with $1.5 \%$ type $\mathrm{V}$ agarose (w/v in RPMI). The cells were incubated at $37^{\circ} \mathrm{C}, 5 \% \mathrm{CO}_{2}$ and monitored at $24 \mathrm{~h}$ for MCTS production. Medium was changed every $48 \mathrm{~h}$ by removing and re-placing $50 \%$ of the medium.

\section{Primary human oral keratinocyte and fibroblast isolation}

Normal oral keratinocytes (NOKs) and fibroblasts (NOFs) were isolated from biopsies obtained from the buccal and gingival oral mucosa from patients during routine dental procedures with written, informed consent (ethical approval number 09/H1308/66) as previously described (Hearnden et al, 2009). Briefly, biopsies were incubated overnight at $4{ }^{\circ} \mathrm{C}$ in $0.1 \% \mathrm{w} / \mathrm{v}$ trypsin solution supplemented with $100 \mathrm{IU} \mathrm{ml}$ penicillin, $100 \mathrm{mg} \mathrm{ml}^{-1}$ streptomycin and $0.625 \mu \mathrm{g} \mathrm{ml}^{-1}$ amphotericin B. Following enzymatic digestion, the epithelium was removed from the connective tissue and oral keratinocytes isolated by gently scraping the papillary surface of the epithelium and the uppermost side of the connective tissue layer. Keratinocytes were cultured on irradiated mouse 3T3 feeder layers in flavin- and adenine-enriched medium.

The NOFs were isolated from the connective tissue by fine mincing followed by digestion with $0.5 \%(\mathrm{w} / \mathrm{v})$ collagenase A overnight at $37^{\circ} \mathrm{C}$. The NOFs were collected by centrifugation and then cultured in DMEM supplemented with $10 \%$ FCS, $2 \mathrm{~mm}$ glutamine, $100 \mathrm{IU} \mathrm{ml}^{-1}$ penicillin and $100 \mu \mathrm{g} \mathrm{ml}^{-1}$ streptomycin. 


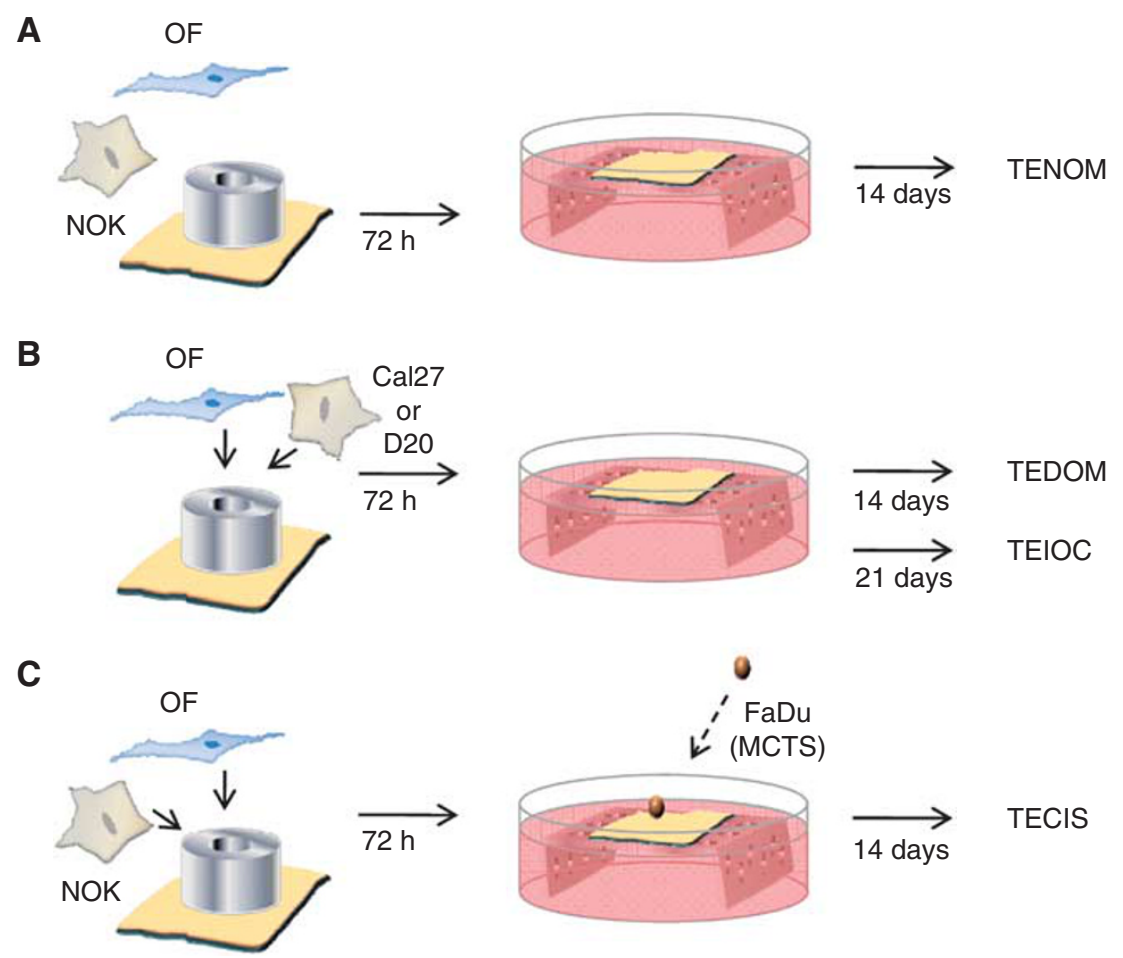

Figure I Schematic illustration showing the methodology for producing the full-thickness tissue-engineered oral mucosal models. To produce the tissueengineered normal oral mucosa model (TENOM), normal oral fibroblasts (OFs) and normal oral keratinocytes (NOKs) were seeded onto a DED scaffold within a $0.8 \mathrm{~cm}^{2}$ steel ring. After $72 \mathrm{~h}$, the composites were raised to an air/liquid interface and cultured for a further 14 days $(\mathbf{A})$. To recreate an in vitro model of dysplastic oral mucosa (TEDOM) and early invasive oral carcinoma (TEIOC), the NOKs were replaced with OSCC cells (Cal27 or D20) and cultured for either 14 or 21 days, respectively (B). The addition of a MCTS to the TENOM produced a model closely mimicking carcinoma in situ (TECIS) (C).

Table I Antibodies and antigen retrieval conditions used in this study

\begin{tabular}{|c|c|c|c|c|}
\hline Marker & Antibody clone & Dilution/final concentration & Antigen retrieval & Source \\
\hline Ki67 & MIB-I & $1: 50$ & 0.01 M sodium citrate buffer & Dako, Copenhagen, Denmark \\
\hline AEI/AE3 & AEI/AE3 & $1: 100$ & 0.01 M sodium citrate buffer & Dako \\
\hline Collagen IV & $\mathrm{COL}-94$ & $1: 500$ & 0.01 M sodium citrate buffer & Sigma, Poole, UK \\
\hline$\alpha \vee \beta 6$ & $6.2 \mathrm{Al}$ & $0.5 \mu \mathrm{g} \mathrm{ml}^{-1}$ & Proteinase $\mathrm{K}$ & Generated as described in Weinreb et al (2004) \\
\hline
\end{tabular}

\section{Production of de-epidermised acellular dermis (DED)}

De-epidermised acellular dermis was produced from either splitthickness skin grafts or commercially available cadaver skin (Euroskin, Beverwijk, Holland) and processed as previously described (Eves et al, 2000). Split-thickness skin grafts were immersed in $1 \mathrm{M}$ sodium chloride for $24 \mathrm{~h}$ at $37^{\circ} \mathrm{C}$ to allow removal of the epidermis. The resultant DED samples were then washed extensively in PBS and stored at $4{ }^{\circ} \mathrm{C}$ in DMEM until use.

\section{Production of tissue-engineered oral mucosal models}

De-epidermised acellular dermis was incubated in fresh DMEM for $48 \mathrm{~h}$ at $37^{\circ} \mathrm{C}$ to confirm sterility. Then, $15 \mathrm{~mm}^{2}$ pieces were transferred to six-well plates (papillary surface uppermost) and an $8 \mathrm{~mm}$ diameter steel ring placed on top of each piece and immersed in medium. Tissue-engineered normal oral mucosa models (TENOM), (Figure $1 \mathrm{~A}$ ) were produced by seeding $5 \times 10^{5}$ NOKs and $5 \times 10^{5}$ NOFs in the centre of the steel ring. For the tissue-engineered dysplastic oral mucosa models (TEDOM, Figure $1 \mathrm{~B}$ ), either $2.5 \times 10^{5} \mathrm{Cal27}$ or D20 cells and $5 \times 10^{5} \mathrm{NOFs}$ were used, and for the tissue-engineered early invasive oral carcinoma (TEIOC, Figure 1B) models, $2.5 \times 10^{5}$ Cal27 cells and $5 \times 10^{5}$ NOFs were used. Medium within the ring was replaced after 24 and $48 \mathrm{~h}$. After $72 \mathrm{~h}$, the ring was removed and the composites placed on to stainless steel grids with medium added to the underside of the composite model to allow culture at the air-toliquid interface. To generate tissue-engineered carcinoma in situ (TECIS), (Figure 1C) models, 7-day-old FaDu MCTS were added to TENOM. For all models, medium was changed 2-3 times a week and the composites fixed at day 14 for TENOM, TEDOM, TECIS and at day 21 for TEIOC in $10 \%$ buffered formalin for $48 \mathrm{~h}$. All models were then bisected and paraffin embedded.

\section{Immunohistochemistry}

Paraffin-embedded tissue sections $(5 \mu \mathrm{m})$ were prepared from tissue-engineered mucosal models and for comparative purposes from paraffin-embedded blocks of NOM and archival HNSCC biopsies in accordance with the Sheffield Research Ethics Committee approval (Ref: 07/H1309/105). Sections were dewaxed, rehydrated and either stained with haematoxylin and eosin (H\&E) or subjected to immunohistochemistry, in which case endogenous peroxidase was neutralised with $3 \%$ hydrogen peroxide for $20 \mathrm{~min}$. Following antigen retrieval, sections were blocked using proteinfree blocking solution (Dako, Copenhagen, Denmark) for $20 \mathrm{~min}$ at room temperature and then mouse monoclonal primary antibody (diluted in PBS) applied for $1 \mathrm{~h}$ at room temperature (see Table 1 
for antibodies, dilutions and antigen retrieval method used). Secondary antibody and avidin-biotin complex $(\mathrm{ABC})$ provided with Vectastain Elite ABC kit (Vector Labs, Peterborough, UK) were then used in accordance with the manufacturer's instructions. Finally, 3'-diaminobenzidine tetrahydrochloride (DAB) (Vector Labs) was used to visualise peroxidase activity and the sections were counterstained with haematoxylin, dehydrated and mounted in DPX. Images were taken using an Olympus BX51 microscope and Colour view IIIu camera with associated Cell $\wedge \mathrm{D}$ software (Olympus Soft Imaging Solutions, GmbH, Münster, Germany).

\section{RESULTS}

\section{Full-thickness tissue-engineered normal oral mucosa model}

To generate a full-thickness TENOM, oral keratinocytes and oral fibroblasts were cultured on a DED scaffold at an air-to-liquid interface for 14 days. The oral keratinocytes migrated and proliferated laterally over the dermis as evident from crosssectional histological analysis with the epithelia at the centre of the composite being thicker and tapering off towards the edges (data not shown). Histologically, the TENOM demonstrated normal architectural morphology, epithelial maturation and surface keratinisation, a convoluted EDJ and a fibroblast-populated dermis that closely replicates the histological appearance of NOM (Figure 2A and F). A similar proliferation index to NOM was evident upon Ki67 staining with proliferating cells predominately located in the basal or para-basal cell layer (Figure 2B and G). The pan-cytokeratin antibody anti-AE1/3 showed positive expression throughout the thickness of the TENOM epithelium with increased intensity in the lower third of the epithelium and was comparable to the NOM (Figure 2C and $\mathrm{H}$ ). Immunohistochemical staining for collagen IV, a component of basement membranes, showed that TENOM forms a basement membrane at the junction of the epithelium and the underlying connective tissue, as well as around vascular spaces in the connective tissue, similar to that seen in NOM (Figure 2D and I). Finally, an antibody against integrin $\alpha v \beta 6$ (Weinreb et al, 2004) revealed positive staining associated with the keratinocytes in the basal cell layer of both NOM and TENOM (Figure 2E and $\mathrm{J}$ ).

\section{Tissue-engineered dysplastic oral mucosa model}

During the transformation from normal to premalignant lesions, normal proliferation and differentiation of the mucosal epithelium is disrupted, resulting in a dysplastic architecture. In dysplastic oral mucosa, the rete processes become rounded, drop-shaped and bulbous, and there is loss of normal keratinocyte maturation. To model these changes in vitro, NOKs used for the TENOM were replaced with the dysplastic cell line D20 or malignant Cal27 cells and again seeded with NOFs on to a DED scaffold. The TEDOM displays architectural and cytological changes typically associated with clinical lesions histologically classified as severely dysplastic. Similar to the clinical lesion, the TEDOM for both D20 and Cal27 cells show bulbous rete processes and abnormal keratinocyte maturation (Figure $3 \mathrm{~A}, \mathrm{~F}$ and $\mathrm{K}$ ). In addition, abnormal keratinocyte proliferation patterns are evident in the models and match that seen in the dysplastic biopsy with proliferating cells extending well into the supra-basal epithelial layers (Figure 3B, G and L). The ratio of ki67-positive cells to nonproliferating cells is similar in the biopsy compared with D20 and Cal27 models and there is an increased proliferation index of Ki67-positive epithelial cells along with abnormally high levels of mitotic figures (Figure $3 \mathrm{~B}, \mathrm{G}$ and $\mathrm{L}$ ). The resultant loss of normal maturation and disrupted keratinocyte differentiation is also evidenced by AE1/3 staining (Figure $3 \mathrm{C}, \mathrm{H}$ and $\mathrm{M}$ ). Further cytokeratin profile staining showed positive expression of CK5/6 in both D20 and Cal27 models, which is characteristic of oral tumours, whereas staining for CK7 (characteristic of lung and ovarian tumours) or CK20 (characteristic of colonic or pancreatic tumours) was negative (data not shown). However, despite these histological changes, immunohistochemical staining for collagen type IV shows a welldefined, continuous basement membrane with no evidence of malignant invasion and clearly mimics the in vivo situation of dysplastic epithelium (Figure $3 \mathrm{D}, \mathrm{I}$ and N). Expression of $\alpha \mathrm{v} \beta 6$ is dramatically changed in DOM where it is expressed erratically throughout the entire epithelium as well as on some basal cells. A similar pattern of $\alpha \mathrm{v} \beta 6$ expression was observed in the TEDOM of D20 and Cal27 models when compared with expression in DOM (Figure 3E, J and O). Similar results to those described above were also found using the dysplastic cell line DOK (Supplementary Figure 1).

\section{Tissue-engineered model of a severely dysplastic epithelium (carcinoma in situ) surrounded by normal oral mucosa}

Biopsies are routinely taken from the visual boundary of the oral lesion to allow histological examination of normal epithelium juxtaposed to diseased tissue. A tissue-engineered model containing both a dysplastic and normal element would therefore be valuable to enable examination of the interface between diseased and normal tissue in parallel. To model this, the OSCC FaDu cell line was cultured as a MCTS (to enable easy manipulation of the cells into the desired position; Cal27 cells do not produce satisfactory MCTS and hence were not used in this model) and incorporated within a TENOM. The model produced a histological picture closely resembling carcinoma in situ with a highly disorganised epithelial architecture showing severe cytological atypia involving the entire thickness of the epithelium and lying adjacent to an otherwise normal epithelium (Figure 4A and F). High proliferation indices with large numbers of Ki67-positive supra-basal keratinocytes for FaDu cells in the TECIS model and dysplastic cells in the oral biopsy were seen in contrast to the typical intermittently Ki67-positive polarised para-basal cells in the adjacent areas of TENOM and NOM (Figure $4 \mathrm{~B}$ and G). In the TECIS model the FaDu cells showed reduced expression of keratins, staining weakly for the pan-cytokeratin marker AE1/3 in comparison with the adjacent 'normal tissue' that was stained throughout the epithelium. This was in contrast to the oral biopsy that showed disrupted $\mathrm{AE} 1 / 3$ cytokeratin staining throughout the dysplastic epithelium (Figure $4 \mathrm{C}$ and $\mathrm{H}$ ). Comparable to the CIS biopsy, FaDu cells in the TECIS did not penetrate the basement membrane and invade into the underlying connective tissue, and a collagen IV-positive intact basement membrane was present in both cases (Figure 4D and I). Expression of $\alpha \mathrm{v} \beta 6$ was weak in both CIS and TECIS and the expression was restricted to the basal epithelial cells (Figure 4E and J). Flow cytometric analysis showed that NOK, DOK, Cal27 and FaDu all express cell surface $\alpha \mathrm{v} \beta 6$ when grown as monolayer cultures (Figure 5), suggesting that expression of this receptor dramatically changes when grown in 3D models and may be associated with a less well-differentiated phenotype.

\section{Tissue-engineered model of early invasive oral squamous cell carcinoma}

The progression from dysplasia to an invasive oral carcinoma is histopathologically defined when islands and cords of malignant epithelial cells arising from the overlying dysplastic mucosa invade through the basement membrane into the lamina propria. To model this, the TEDOM was further cultured for another 7 days, by which time histological analysis revealed that tumour cells had infiltrated the basement membrane and invaded the underlying stroma as evident by the presence of tumour islands within the connective tissue (Figure 6A and F). Similar results were observed 

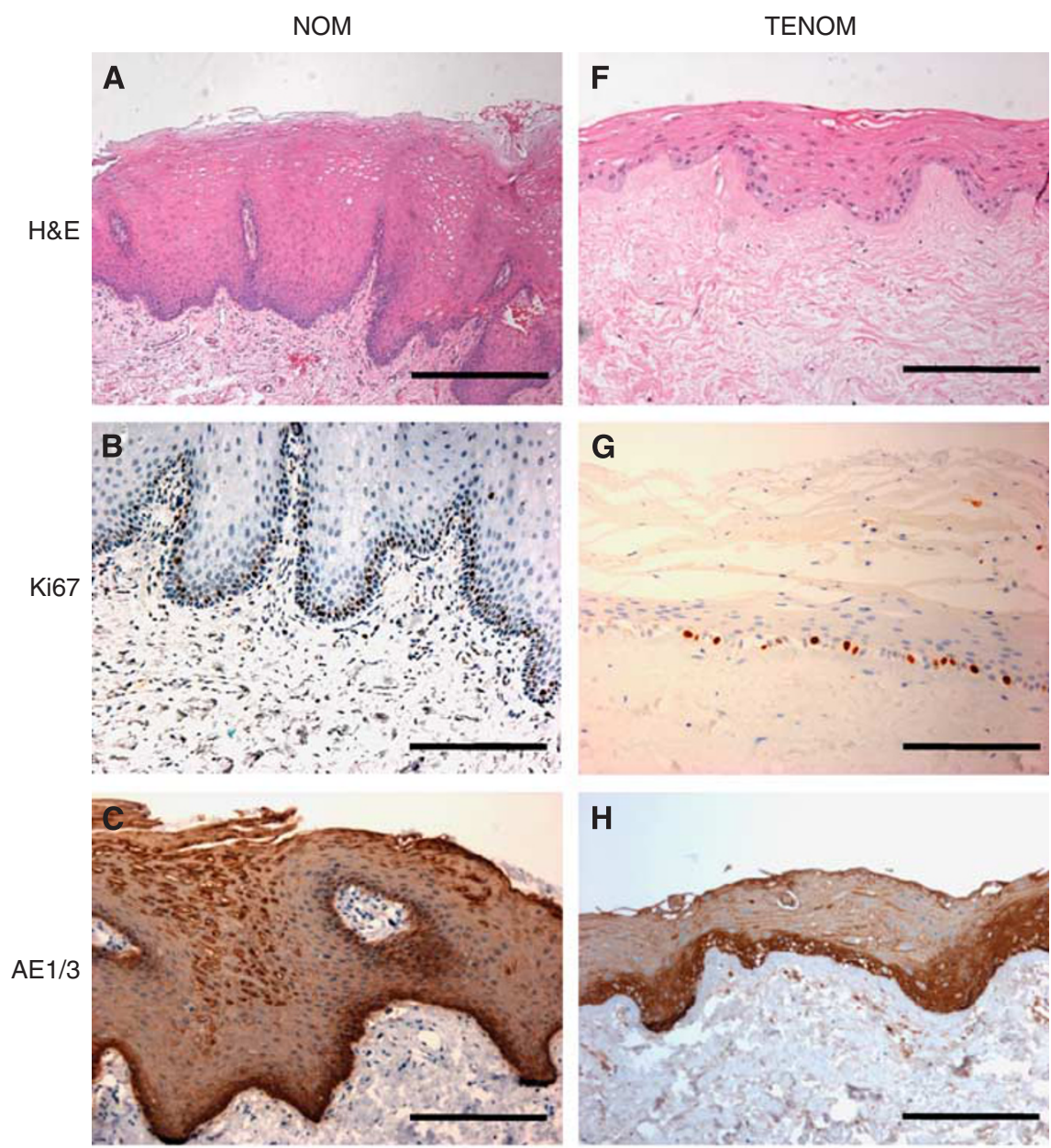

H
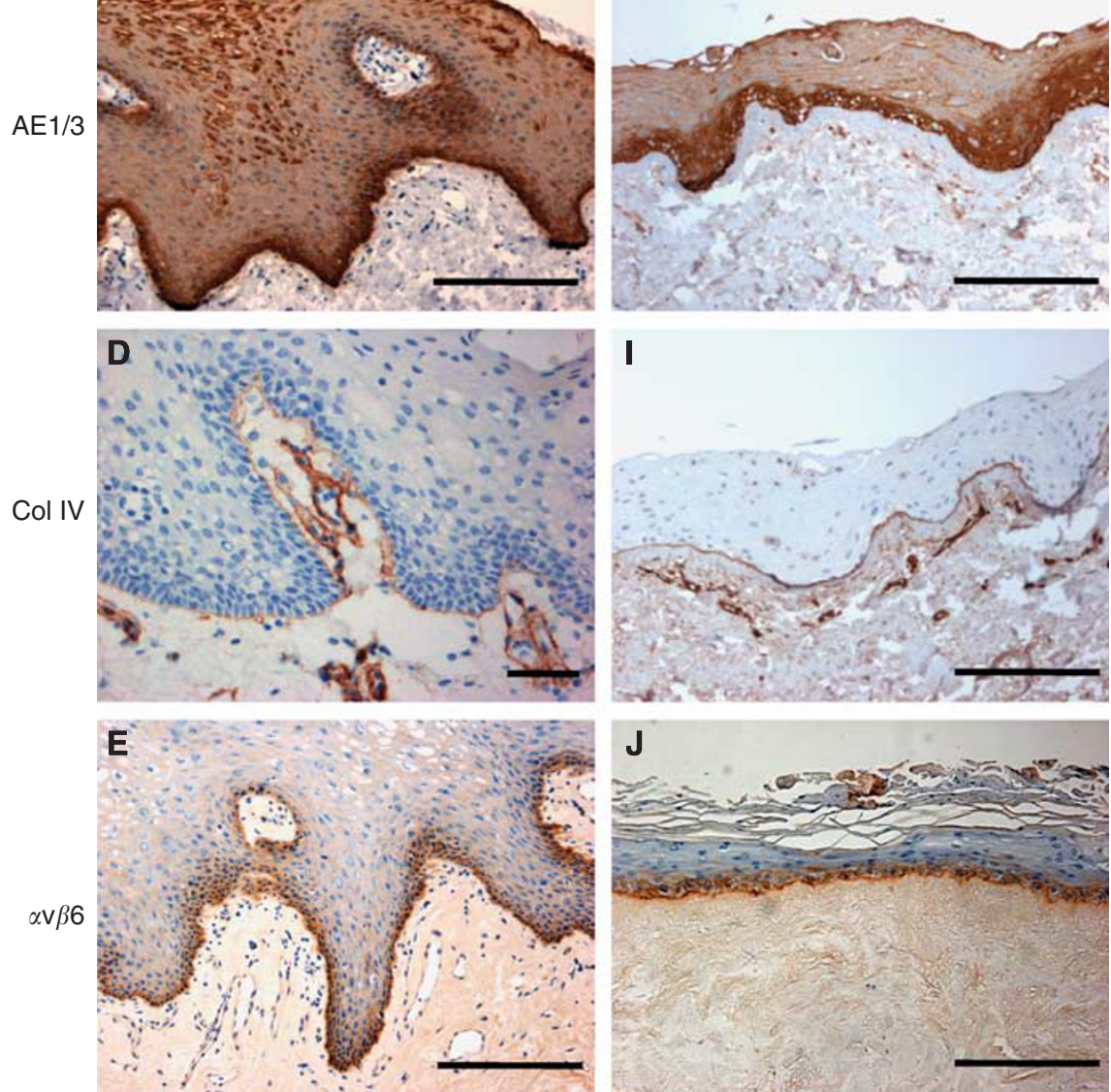

Figure 2 Representative sections of normal oral mucosa taken from patient biopsies (NOM) (A-E) and tissue-engineered normal oral mucosa constructs (TENOM) $(\mathbf{F}-\mathbf{J})$. TENOM models were generated by culturing normal oral keratinocytes and normal oral fibroblasts on DED at an air/liquid interface for I4 days. Sections have been stained with H\&E ( $\mathbf{A}$ and $\mathbf{F}$ ) and immunohistochemically stained to show the pattern of expression of Ki67 (B and G), AEI/3 (C and $\mathbf{H})$, collagen type IV (Col IV; D and $\mathbf{I})$ and integrin $\alpha \vee \beta 6$ (E and $\mathbf{J})$ and counterstained with haematoxylin. Scale bar indicates $200 \mu \mathrm{m}$.

when TEIOC models were made from the OSCC cell lines SCC9, SCC25, PE/CA-PJ34 and FaDu, and then cultured for 14-21 days at an air-to-liquid interface. In contrast, the OSCC cell line SCC4 failed to generate TEIOC models (Supplementary Figure 2). Immunohistochemical analysis confirmed that this TEIOC represents a histological picture of naturally occurring early invasive 

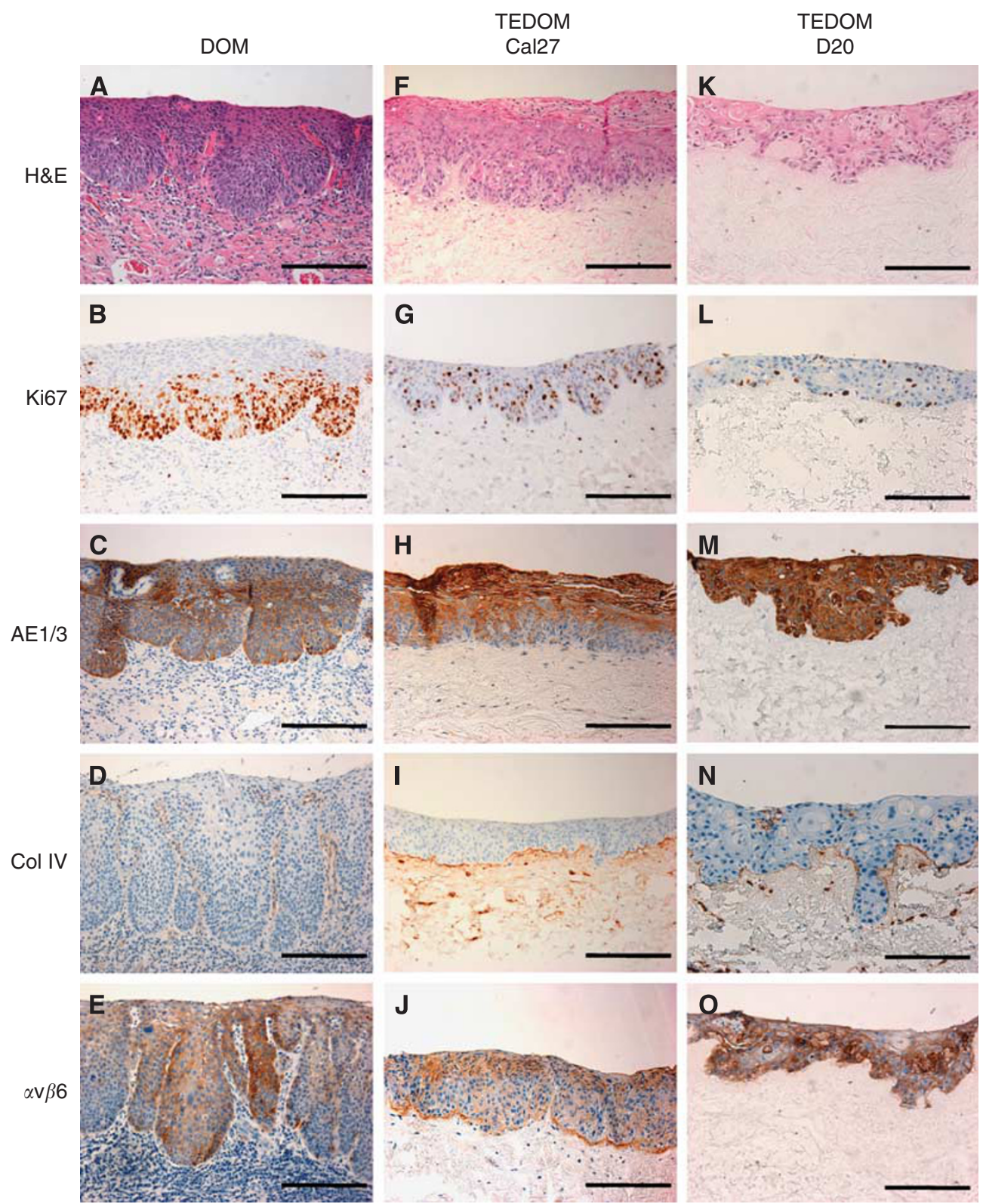

Figure 3 Representative sections of dysplastic oral mucosa taken from patient biopsies (DOM) (A-E) and tissue-engineered dysplastic oral mucosa constructs (TEDOM) $(\mathbf{F}-\mathbf{J})$. TEDOM models were generated by culturing D20 or Cal27 cells and normal oral fibroblasts on DED at an air-to-liquid interface for 14 days. Sections were stained with $\operatorname{H\& E}(\mathbf{A}, \mathbf{F}$ and $\mathbf{K})$ and immunohistochemically stained to show the pattern of expression of Ki67 (B, G and $\mathbf{L})$, AEI/3 $(\mathbf{C}, \mathbf{H}$ and $\mathbf{M})$, collagen type IV (Col IV; D, I and $\mathbf{N})$ and integrin $\alpha \vee \beta 6(\mathbf{E}, \mathbf{J}$ and $\mathbf{O})$ and counterstained with haematoxylin. Scale bar indicates $200 \mu \mathrm{m}$.

OSCC. Positive staining for pan-cytokeratin and cytokeratin 5/6 and negative staining for cytokeratin 7 and 20 confirmed that the invaded cells were of oral epithelial origin (Figure 6C and $\mathrm{H}$, and data not shown). Collagen type IV staining showed that the basement membrane along the EDJ was completely disrupted and replicates the in vivo situation (Figure 6D and I). Although the epithelial cells in the invasive cancer model are not as proliferative as in the invasive OSCC, the TEIOC shows an abnormal proliferation profile with cells staining positively for ki67 throughout the epithelium and proliferating cells within the invading tumour island (Figure 6B and G). Expression of $\alpha \mathrm{v} \beta 6$ was patchy but widely distributed throughout the dysplastic epithelium as well as in the islands of invasive OSCC, but expression was weak in the TEIOC model (Figure 6E and J) despite flow cytometric analysis showing strong $\alpha \mathrm{v} \beta 6$ staining on monolayer cultures (Figure 5C).

\section{DISCUSSION}

In this study we present the development of a tissue-engineered 3D model of the oral mucosa using a native complex dermal matrix to produce three in vitro models demonstrating histopathological malignant transformation through dysplasia, carcinoma in situ to early invasive carcinoma. The models were closely compared with their in vivo counterpart with regard to the architectural and cytological changes observed. Furthermore, we used the models to investigate the expression of the integrin $\alpha \mathrm{v} \beta 6$ at different stages of cancer progression and compared these with patient biopsies, as dysregulated expression of this integrin has been previously associated with dysplasia and carcinogenesis (Thomas et al, 2001b; Nystrom et al, 2006).

Histological examination of the TENOM revealed that normal keratinocytes proliferated to produce a stratified squamous 

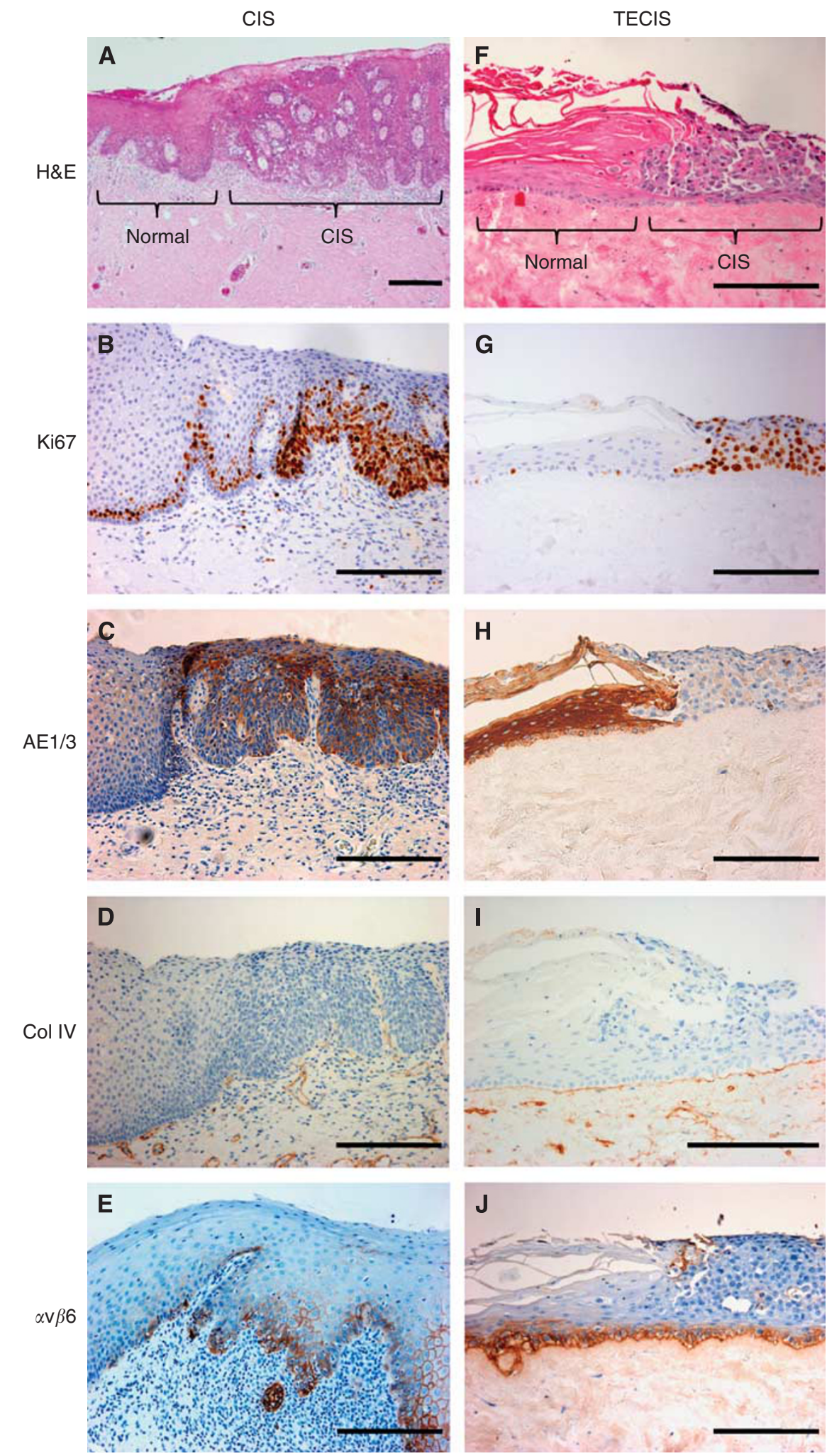

Figure 4 Representative sections of oral mucosa taken from patient biopsies pathohistologically classified as carcinoma in situ (CIS) (A-E) and a tissueengineered model of carcinomas in situ (TECIS) $(\mathbf{F}-\mathbf{J})$. TECIS models were generated by the addition of a MCTS to the TENOM model and further culture at an air/liquid interface for I 4 days. Sections have been stained with H\&E ( $\mathbf{A}$ and $\mathbf{F})$ and immunohistochemically stained to show the pattern of expression of Ki67 (B and $\mathbf{G}), A E I / 3(\mathbf{C}$ and $\mathbf{H})$, collagen type IV (Coll IV; $\mathbf{D}$ and $\mathbf{I})$ and integrin $\alpha \vee \beta 6$ (E and $\mathbf{J}$ ) and counterstained with haematoxylin. Scale bar indicates $200 \mu \mathrm{m}$. In each case, relatively normal tissue is seen to the left and CIS to the right of each section. 
A

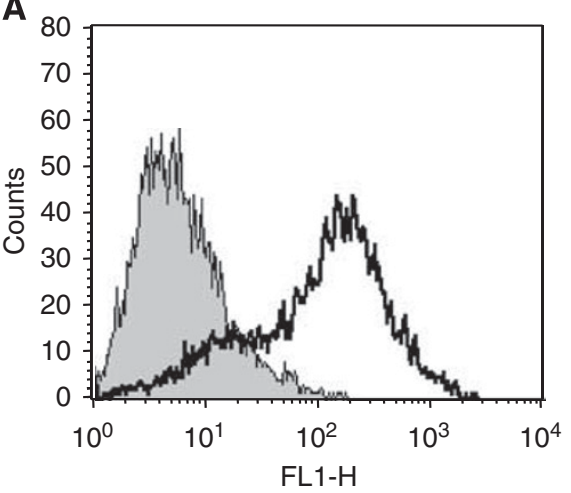

C

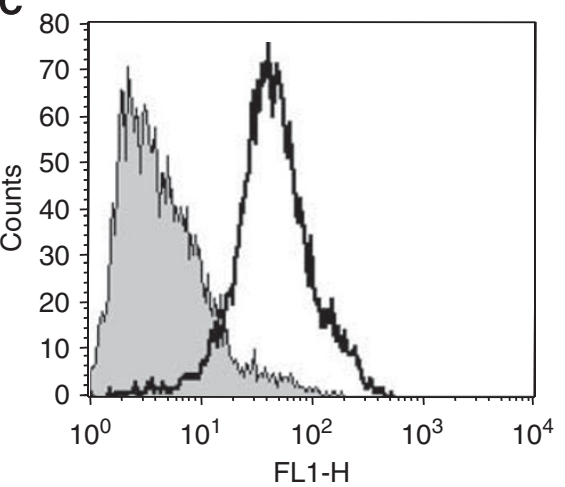

B

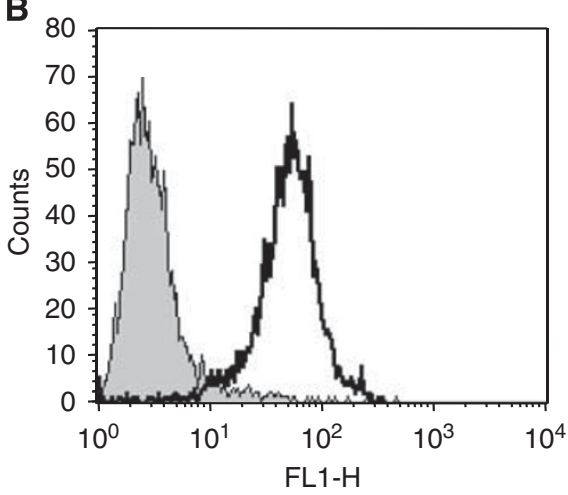

D

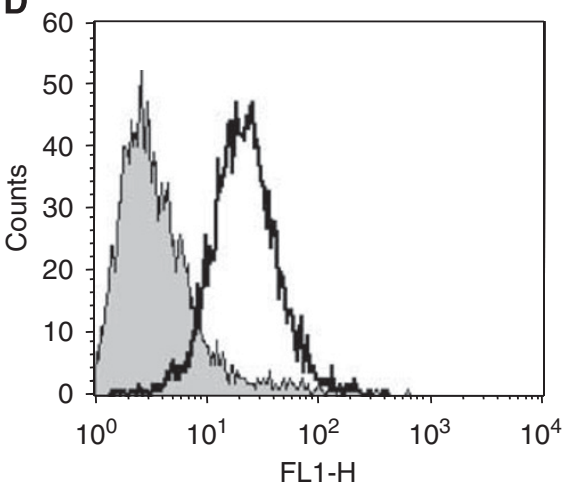

Figure 5 Flow cytometric analysis showing expression of cell surface $\alpha v \beta 6$ on monolayer cultures of normal oral keratinocytes (A), DOK (B), Cal27 (C) and $\mathrm{FaDu}(\mathbf{D})$. Histograms show expression of $\alpha v \beta 6$ (open histogram) compared with isotype-matched control lgG (grey-filled histogram). The $x$ axis is log scale fluorescence.

epithelium several layers thick that is consistent with previously published reports (Cho et al, 2000; Bhargava et al, 2004; Moharamzadeh et al, 2008). To produce a model of oral dysplasia, NOKs were substituted with the dysplastic cell line, D20, or the malignant OSCC cell line, Cal27. The histological changes observed in both our TEDOM models are typical for a lesion classified as premalignant dysplasia with increased numbers of proliferating keratinocytes that are abnormally located in the supra-basal layers and a degree of atypical maturation and architecture.

Dysplastic keratinocytes derived from clinical lesions have an altered phenotype when cultured as $3 \mathrm{D}$ constructs with the degree of dysplasia not matching that of the original lesion (Gaballah et al, 2008). This may be because lesions are a heterogeneous mix of keratinocytes at different developmental stages and more atypical cells may possess a survival advantage in culture (Gaballah et al, 2008). The aim of the current study was to produce a model system that could easily be reproduced. The advantages of using a dysplastic cell line include reproducibility, standardisation and to avoid donor-dependant variations including age and site of isolation, which often arise when using donor-derived cells. Morphological and cytological changes are also consistent through serial passage for immortal cell lines, which is not the case for mortal dysplastic keratinocytes (Gaballah et al, 2008). Costea et al (2006) showed that DOK cells were invasive in collagen-based connective tissue organotypic models, whereas we found DOK cells to be noninvasive in our native DED-based models. The DOK cells are also nontumourigenic in mice (Chang et al, 1992), suggesting that their invasion capacity is restricted by native ECM but not by collagen alone and underscores the importance of using DED in models of dysplasia.

True to the malignant progression of OSCC, further culture of the Cal27 TEDOM led to breakdown of the basement membrane and extensive epithelial tumour cell invasion into the connective tissue component of the model that was analogous to early invasive OSCC in vivo. Stromal fibroblasts appear to be crucial for tumour invasion and progression (Kalluri and Zeisberg, 2006). During transition from normal epithelium to malignancy, some fibroblasts transdifferentiate into $\alpha$-smooth muscle actin-expressing myofibroblasts that facilitate oral tumour cell invasion (Lim et al, 2011; Marsh et al, 2011). In this study marked invasion into the connective tissue of the TEIOC model was evident even in the presence of normal human oral fibroblasts (NOFs were $\alpha$-smooth muscle actin negative by immunohistochemistry; data not shown). Using collagen-based models, Marsh et al (2011) showed increased invasion of OSCC cells into the ECM in the presence of myofibroblasts compared with NOFs, and no invasion was observed in models without fibroblasts (Marsh et al, 2011). This suggests that OSCC invasion into the DED of our models may be further enhanced if myofibroblasts were used in place of NOFs.

Immunohistochemical analysis has shown that expression of integrin $\alpha \mathrm{v} \beta 6$ is altered during the transition from NOM though premalignant lesions to invasive oral cancer (Thomas et al, 1997, 2001b; Nystrom et al, 2006). It is also upregulated in mucosal development, wound healing and areca (betel) nut-mediated oral submucous fibrosis (Nystrom et al, 2006; Thomas et al, 2006; Moutasim et al, 2011). The $\alpha \mathrm{v} \beta 6$ integrin appears to play an important role in oral cancer cell invasion by directly upregulating the expression of matrix metalloproteinase- 9 and indirectly by activating TGF- $\beta$ that then promotes myofibroblast formation (Thomas et al, 2001a; Lewis et al, 2004). The $\alpha \mathrm{v} \beta 6$-dependent OSCC invasion also requires COX-2-dependent activation of Rac-1, via upregulation of $\mathrm{PGE}_{2}$ (Nystrom et al, 2006). Similar to the normal in vivo situation, we found $\alpha \mathrm{v} \beta 6$ expression localised to the basal cells of the mucosal models even though flow cytometric analysis showed abundant cell surface expression on all epithelial 

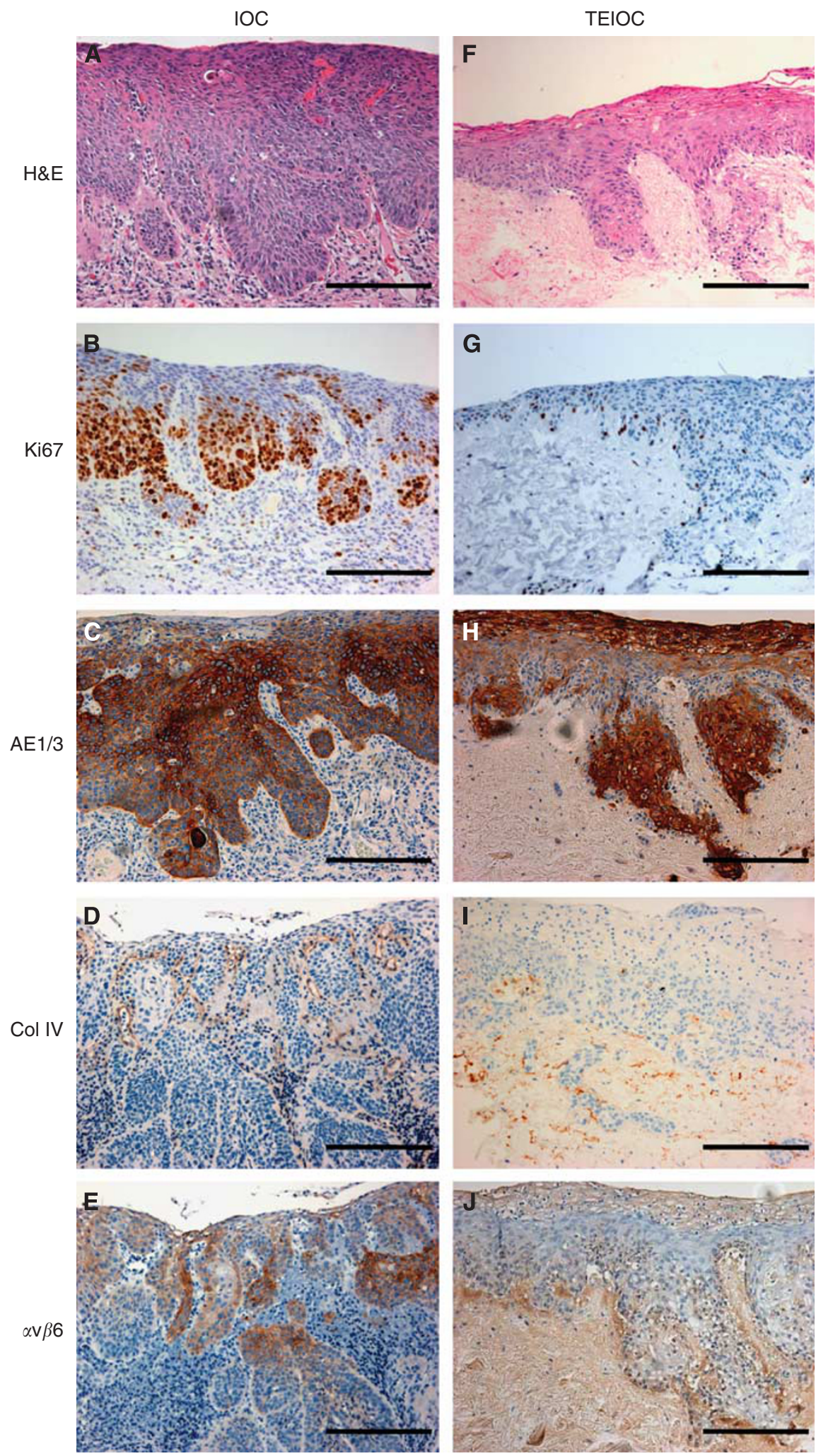

Figure 6 Representative sections of early invasive oral carcinoma (IOC) taken from patient biopsies $(\mathbf{A}-\mathbf{E})$ and a tissue-engineered invasive carcinoma (TEIOC) $(\mathbf{F}-\mathbf{J})$. TEIOC were generated by culturing OSCC (Cal27) and normal oral fibroblasts on DED at an air/liquid interface for 21 days. Sections have been stained with H\&E (A and $\mathbf{F})$ and immunohistochemically stained to show the pattern of expression of Ki67 (B and $\mathbf{G}), A E I / 3$ (C and $\mathbf{H})$, collagen type IV (Col IV; D and I) and integrin $\alpha \vee \beta 6$ (E and J) and counterstained with haematoxylin. Scale bar indicates $200 \mu \mathrm{m}$.

cells before seeding onto the DED, showing that $3 \mathrm{D}$ culture alters the expression pattern of these molecules. Furthermore, similar $\alpha \mathrm{v} \beta 6$ expression patterns were observed in both dysplastic and invasive models when compared with biopsy, providing evidence of the usefulness of these models in mimicking the situation in vivo. The dysplastic and invasive models may therefore be 
useful in future studies aimed at identifying the underlying mechanisms of $\alpha \mathrm{v} \beta 6$-mediated tumour cell invasion.

One consideration, when producing the composites, was the ability to model the transformation from a dysplastic to an invasive phenotype. It was therefore important that the structural integrity of the $3 \mathrm{D}$ construct was maintained throughout the culture period. Bovine or rat-based collagen is often used for $3 \mathrm{D}$ organotypic models because of their ease of use and reproducibility, but these lack the complex structural heterogeneity and degree of collagen fibre crosslinking that is present in mature human oral connective tissue and they are not biostable over long culture periods with artificial invasion possible (Wolf et al, 2009). Furthermore, we and others have shown that these models do not contain a well-defined, continuous basement membrane between the epithelium and the connective tissue that is crucial in the morphological development of the epithelium and its attachment to the connective tissue (Chung et al, 1997; Ralston et al, 1999; Yadev et al, 2011) as well as in defining the boundary of tumour invasion. The collagen composition, organisation, fibre size and orientation that produce heterogeneous pore sizes within the DED are similar to what is seen in vivo (Wolf et al, 2009). Therefore, the use of DED more closely models the connective tissue element of the oral mucosa compared with collagen gels and enables longterm culture of the models for up to 28 days. We suggest that the complex nature of DED is the most physiologically relevant material to test the ability of tumour cells to invade into the connective tissue in vitro. However, these models do not contain a vasculature or immune cell component that may influence tumour cell invasion and hence may not be truly representative of in vivo invasion.

In summary, we have established a novel 3D model of oral dysplasia, carcinoma in situ and early invasive carcinoma that allows the study of architectural and cytological changes within a multilayered construct in a controlled microenvironment. The use of cell lines and commercially available DED ensures that the model is reproducible. Further applications could involve use in final-stage anticancer drug screenings or adaptation of this model to study other diseases and systems.

\section{ACKNOWLEDGEMENTS}

We thank Dr Issam Bakri and Mrs Christine Freeman for their help with collecting patient biopsies, and Dr Keith Hunter for providing the D20 dysplastic cells. This work was funded by Yorkshire Cancer Research, UK.

\section{Conflict of interest}

The authors declare no conflict of interest.

Supplementary Information accompanies the paper on British Journal of Cancer website (http://www.nature.com/bjc)

\section{REFERENCES}

Allen-Hoffmann BL, Rheinwald JG (1984) Polycyclic aromatic hydrocarbon mutagenesis of human epidermal keratinocytes in culture. Proc Natl Acad Sci USA 81: 7802-7806

Argiris A, Karamouzis MV, Raben D, Ferris RL (2008) Head and neck cancer. Lancet 371: 1695-1709

Bhargava S, Chapple CR, Bullock AJ, Layton C, MacNeil S (2004) Tissueengineered buccal mucosa for substitution urethroplasty. BJU Int 93: 807-811

Bhargava S, Patterson JM, Inman RD, MacNeil S, Chapple CR (2008) Tissue-engineered buccal mucosa urethroplasty-clinical outcomes. Eur Urol 53: 1263 - 1269

Braakhuis BJ, Tabor MP, Kummer JA, Leemans CR, Brakenhoff RH (2003) A genetic explanation of Slaughter's concept of field cancerization: evidence and clinical implications. Cancer Res 63: 1727-1730

Bradley G, Odell EW, Raphael S, Ho J, Le LW, Benchimol S, Kamel-Reid S (2010) Abnormal DNA content in oral epithelial dysplasia is associated with increased risk of progression to carcinoma. $\mathrm{Br} J$ Cancer 103: $1432-1442$

Califano J, van der Riet P, Westra W, Nawroz H, Clayman G, Piantadosi S, Corio R, Lee D, Greenberg B, Koch W, Sidransky D (1996) Genetic progression model for head and neck cancer: implications for field cancerization. Cancer Res 56: $2488-2492$

Califano J, Westra WH, Meininger G, Corio R, Koch WM, Sidransky D (2000) Genetic progression and clonal relationship of recurrent premalignant head and neck lesions. Clin Cancer Res 6: 347-352

Carlsson J, Yuhas JM (1984) Liquid-overlay culture of cellular spheroids. Recent Results Cancer Res 95: 1-23

Chang SE, Foster S, Betts D, Marnock WE (1992) DOK, a cell line established from human dysplastic oral mucosa, shows a partially transformed non-malignant phenotype. Int J Cancer 52: 896-902

Cho KH, Ahn HT, Park KC, Chung JH, Kim SW, Sung MW, Kim KH, Chung PH, Eun HC, Youn JI (2000) Reconstruction of human hardpalate mucosal epithelium on de-epidermized dermis. J Dermatol Sci 22: $117-124$

Chung JH, Cho KH, Lee DY, Kwon OS, Sung MW, Kim KH, Eun HC (1997) Human oral buccal mucosa reconstructed on dermal substrates: a model for oral epithelial differentiation. Arch Dermatol Res 289: 677-685

Costea DE, Kulasekara K, Neppelberg E, Johannessen AC, Vintermyr OK (2006) Species-specific fibroblasts required for triggering invasiveness of partially transformed oral keratinocytes. Am J Pathol 168: 1889- 1897
Eves P, Layton C, Hedley S, Dawson RA, Wagner M, Morandini R, Ghanem G, Mac Neil S (2000) Characterization of an in vitro model of human melanoma invasion based on reconstructed human skin. Br J Dermatol 142: $210-222$

Fusenig NE, Breitkreutz D, Dzarlieva RT, Boukamp P, Bohnert A, Tilgen W (1983) Growth and differentiation characteristics of transformed keratinocytes from mouse and human skin in vitro and in vivo. $J$ Invest Dermatol 81: 168s-175s

Gaballah K, Costea DE, Hills A, Gollin SM, Harrison P, Partridge M (2008) Tissue engineering of oral dysplasia. J Pathol 215: 280-289

Gioanni J, Fischel JL, Lambert JC, Demard F, Mazeau C, Zanghellini E, Ettore F, Formento P, Chauvel P, Lalanne CM (1988) Two new human tumor cell lines derived from squamous cell carcinomas of the tongue: establishment, characterization and response to cytotoxic treatment. Eur I Cancer Clin Oncol 24: 1445-1455

Ha PK, Benoit NE, Yochem R, Sciubba J, Zahurak M, Sidransky D, Pevsner J, Westra WH, Califano J (2003) A transcriptional progression model for head and neck cancer. Clin Cancer Res 9: 3058-3064

Hearnden V, Lomas H, Macneil S, Thornhill M, Murdoch C, Lewis A, Madsen J, Blanazs A, Armes S, Battaglia G (2009) Diffusion studies of nanometer polymersomes across tissue engineered human oral mucosa. Pharm Res 26: $1718-1728$

Hunter KD, Thurlow JK, Fleming J, Drake PJ, Vass JK, Kalna G, Higham DJ, Herzyk P, Macdonald DG, Parkinson EK, Harrison PR (2006) Divergent routes to oral cancer. Cancer Res 66: 7405-7413

Jefferies S, Foulkes WD (2001) Genetic mechanisms in squamous cell carcinoma of the head and neck. Oral Oncol 37: 115-126

Kalluri R, Zeisberg M (2006) Fibroblasts in cancer. Nat Rev Cancer 6: 392 - 401 Kim S (2009) Animal models of cancer in the head and neck region. Clin Exp Otorhinolaryngol 2: 55-60

Leemans CR, Braakhuis BJ, Brakenhoff RH (2011) The molecular biology of head and neck cancer. Nat Rev Cancer 11: 9-22

Lewis MP, Lygoe KA, Nystrom ML, Anderson WP, Speight PM, Marshall JF, Thomas GJ (2004) Tumour-derived TGF-betal modulates myofibroblast differentiation and promotes HGF/SF-dependent invasion of squamous carcinoma cells. Br J Cancer 90: 822-832

Lim KP, Cirillo N, Hassona Y, Wei W, Thurlow JK, Cheong SC, Pitiyage G, Parkinson EK, Prime SS (2011) Fibroblast gene expression profile reflects the stage of tumour progression in oral squamous cell carcinoma. J Pathol 223: 459-469 
Mao L, El-Naggar AK, Papadimitrakopoulou V, Shin DM, Shin HC, Fan Y, Zhou X, Clayman G, Lee JJ, Lee JS, Hittelman WN, Lippman SM, Hong WK (1998) Phenotype and genotype of advanced premalignant head and neck lesions after chemopreventive therapy. J Natl Cancer Inst 90: $1545-1551$

Marsh D, Suchak K, Moutasim KA, Vallath S, Hopper C, Jerjes W, Upile T, Kalavrezos N, Violette SM, Weinreb PH, Chester KA, Chana JS, Marshall JF, Hart IR, Hackshaw AK, Piper K, Thomas GJ (2011) Stromal features are predictive of disease mortality in oral cancer patients. J Pathol 223: $470-481$

McGregor F, Wagner E, Felix D, Soutar D, Parkinson K, Harrison PR (1997) Inappropriate retinoic acid receptor-beta expression in oral dysplasias: correlation with acquisition of the immortal phenotype. Cancer Res 57: $3886-3889$

Moharamzadeh K, Brook IM, Van Noort R, Scutt AM, Smith KG, Thornhill MH (2008) Development, optimization and characterization of a fullthickness tissue engineered human oral mucosal model for biological assessment of dental biomaterials. J Mater Sci Mater Med 19: 1793-1801

Moharamzadeh K, Brook IM, Van Noort R, Scutt AM, Thornhill MH (2007) Tissue-engineered oral mucosa: a review of the scientific literature. J Dent Res 86: 115 - 124

Moutasim KA, Jenei V, Sapienza K, Marsh D, Weinreb PH, Violette SM, Lewis MP, Marshall JF, Fortune F, Tilakaratne WM, Hart IR, Thomas G (2011) Betel-derived alkaloid up-regulates keratinocyte alphavbeta6 integrin expression and promotes oral submucous fibrosis. J Pathol 223: $366-377$

Mueller MM, Fusenig NE (2004) Friends or foes - bipolar effects of the tumour stroma in cancer. Nat Rev Cancer 4: 839-849

Nystrom ML, McCulloch D, Weinreb PH, Violette SM, Speight PM, Marshall JF, Hart IR, Thomas GJ (2006) Cyclooxygenase-2 inhibition suppresses alphavbeta6 integrin-dependent oral squamous carcinoma invasion. Cancer Res 66: 10833-10842

Nystrom ML, Thomas GJ, Stone M, Mackenzie IC, Hart IR, Marshall JF (2005) Development of a quantitative method to analyse tumour cell invasion in organotypic culture. J Pathol 205: 468-475

Prime SS, Rosser TJ, Scully C (1986) Site-specific distribution of epithelial cell-surface carbohydrates in rat oral mucosa. Differentiation 31: 35-41

Ralston DR, Layton C, Dalley AJ, Boyce SG, Freedlander E, Mac Neil S (1999) The requirement for basement membrane antigens in the production of human epidermal/dermal composites in vitro. $\mathrm{Br} J$ Dermatol 140: 605-615

Rangan SR (1972) A new human cell line ( $\mathrm{FaDu}$ ) from a hypopharyngeal carcinoma. Cancer 29: 117-121
Reibel J (2003) Prognosis of oral pre-malignant lesions: significance of clinical, histopathological, and molecular biological characteristics. Crit Rev Oral Biol Med 14: 47-62

Rhee JC, Khuri FR, Shin DM (2004) Advances in chemoprevention of head and neck cancer. Oncologist 9: 302-311

Rudin CM, Cohen EE, Papadimitrakopoulou VA, Silverman Jr S, Recant W, El-Naggar AK, Stenson K, Lippman SM, Hong WK, Vokes EE (2003) An attenuated adenovirus, ONYX-015, as mouthwash therapy for premalignant oral dysplasia. J Clin Oncol 21: 4546-4552

Saintigny G, Bonnard M, Damour O, Collombel C (1993) Reconstruction of epidermis on a chitosan cross-linked collagen-GAG lattice: effect of fibroblasts. Acta Derm Venereol 73: 175-180

Thomas GJ, Jones J, Speight PM (1997) Integrins and oral cancer. Oral Oncol 33: $381-388$

Thomas GJ, Lewis MP, Hart IR, Marshall JF, Speight PM (2001a) AlphaVbeta6 integrin promotes invasion of squamous carcinoma cells through up-regulation of matrix metalloproteinase-9. Int J Cancer 92: $641-650$

Thomas GJ, Lewis MP, Whawell SA, Russell A, Sheppard D, Hart IR, Speight PM, Marshall JF (2001b) Expression of the alphavbeta6 integrin promotes migration and invasion in squamous carcinoma cells. J Invest Dermatol 117: 67-73

Thomas GJ, Nystrom ML, Marshall JF (2006) Alphavbeta6 integrin in wound healing and cancer of the oral cavity. J Oral Pathol Med 35: $1-10$

Torres-Rendon A, Stewart R, Craig GT, Wells M, Speight PM (2009) DNA ploidy analysis by image cytometry helps to identify oral epithelial dysplasias with a high risk of malignant progression. Oral Oncology 45: $468-473$

Vigneswaran N, Beckers S, Waigel S, Mensah J, Wu J, Mo J, Fleisher KE, Bouquot J, Sacks PG, Zacharias W (2006) Increased EMMPRIN (CD 147) expression during oral carcinogenesis. Exp Mol Pathol 80: 147-159

Weinreb PH, Simon KJ, Rayhorn P, Yang WJ, Leone DR, Dolinski BM, Pearse BR, Yokota Y, Kawakatsu H, Atakilit A, Sheppard D, Violette SM (2004) Function-blocking integrin alphavbeta6 monoclonal antibodies: distinct ligand-mimetic and nonligand-mimetic classes. J Biol Chem 279: $17875-17887$

Wolf K, Alexander S, Schacht V, Coussens LM, von Andrian UH, van Rheenen J, Deryugina E, Friedl P (2009) Collagen-based cell migration models in vitro and in vivo. Semin Cell Dev Biol 20: 931 - 941

Yadev NP, Murdoch C, Saville SP, Thornhill MH (2011) Evaluation of tissue engineered models of the oral mucosa to investigate oral candidiasis. Microb Pathog 50: 278-285

This work is published under the standard license to publish agreement. After 12 months the work will become freely available and the license terms will switch to a Creative Commons Attribution-NonCommercial-Share Alike 3.0 Unported License. 